\title{
DETERMINATION OF RHEOLOGICAL MODEL COEFFICIENTS OF PIPELINE COMPOSITE MATERIAL LAYERS BASED ON SPECTRUM ANALYSIS AND OPTIMIZATION
}

\author{
Marijonas Bogdevičius, Mykola Karpenko, Paulius Bogdevičius \\ Vilnius Gediminas Technical University, Department of Mobile Machinery and Railway Transport, Vilnius, Lithuania \\ e-mail:marijonas.bogdevicius@vilniustech.lt; mykola.karpenko@vilniustech.lt; paulius.bogdevicius@vilniustech.lt
}

\begin{abstract}
The article presents theoretical and experimental investigation on properties of a composite material based on rubber. The approach presented in this research is an experimental measurement based on spectrum analysis combined with theoretical investigation held to describe a viscous-elastic behaviour of the material. The proposed mathematical model is represented by five rheological parameters of hybrid Maxwell and Kelvin-Voigt elements and includes an optimization task for determination of the stiffness and damping coefficients. In the proposed rheological model, not only the displacements are unknown but also forces described by second-order differential equations. Validation between the experimental measurement and theoretical investigation is made based on spectrum analysis.
\end{abstract}

Keywords: composite material, pipeline, spectrum analysis, rheological model, optimization

\section{Introduction}

Composites based on rubber are one of the modern material groups with an increasing number of applications ranging in different areas of transport (Bogdevičius et al., 2017) like fire track systems, Fig. 1a, and vehicle component (Korunović et al., 2019) Fig. 1b. At the same time, with a subsequent decrease in the price and a number of advantages of making use of composites, they becomes more and more attractive (Das et al., 2016). These two factors make the necessity for the assessment of mechanical properties of such composites.

(a)

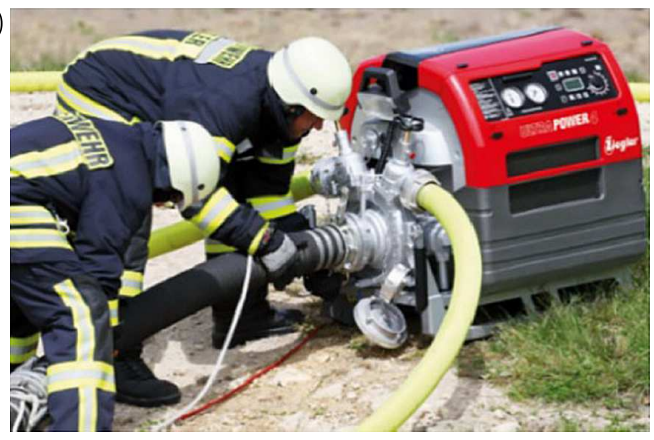

(b)

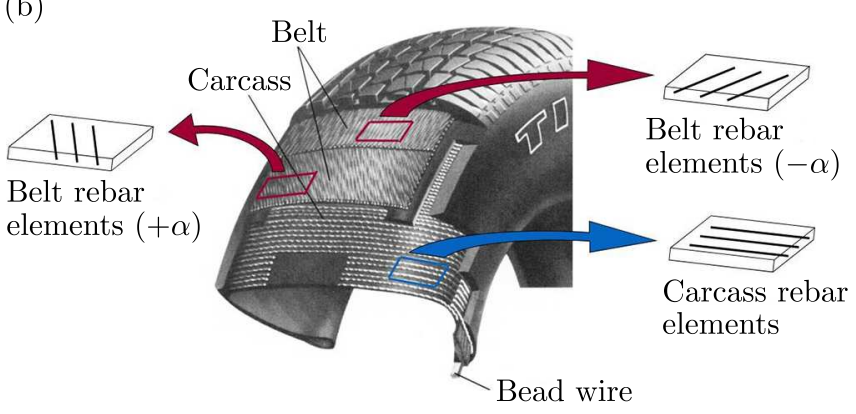

Fig. 1. Example of using composites based on rubber: (a) centrifugal pump with a composite pipeline used in fire truck applications (Bogdevičius et al., 2017), (b) vehicle part - composite tire

(Korunović et al., 2019)

Theoretical and experimental research on the determination of elastic and dynamic properties of composite materials has already started (Dannemann et al., 2019), but the damping properties are still difficult to assess and difficult to include in the analysis and at the design stage according to Treviso et al. (2015). In several types of research, for example in Wesolowski and Barkanov 
(2016), real dynamic properties of materials hard to simulate and describe mathematically are pointed out because experimental measuring is extremely exposed to extraneous damping present during tests. Composite materials refer to multilayer objects according to Cho (2016), so it should be remembered that investigation of multilayer models is a complex and time-consuming task, Bogdevičius et al. (2019).

To determinate dynamic properties of composite materials one can perform various tests, for example Dannemann et al. (2017) and Szymczak and Kowalewski (2020), based on vibroacoustic and strength tests under tensile load. However, investigation on the behaviour and mechanical characteristics of rubber should be done first (for rubber matrix composites). This investigation can use a uniaxial compression test under quasi static and high strain rate loading conditions as provided by Baranowski et al. (2017). According to Zhao et al. (2019), the most frequently used methods for experimental determination of the dynamic properties of materials are various combinations of destructive measurement methods for determination of stiffness properties (Langdon et al., 2013) and non-destructive measurement methods for determination of material damping (Wesolowski and Barkanov, 2016). At the same time, to correct the investigation of composite materials behaviour one should take in account the loads under which the object belongs to during operation, see Wang et al. (2013). That is why the experimental research with combination of computational as well as advanced constitutive modeling should cover a wide range of investigation methods for improving composite materials. According to Baranowski et al. (2020), the investigation of composite materials undergoing a loading can be realized to improve blast resistance of objects and, according to Abe et al. (2004), can be optimized for material structures by combining a finite element method approach with mathematical programming and a genetic algorithm. At the same time, the damping properties of composite materials and their nomenclature are contradictory and, therefore, the obtained values often require approximate transformations. Therefore, it is recommended according to Avril et al. (2008), to take great care when comparing damping values measured by different methods and in different environments with taking in account the frequency response of the material.

Additionally, in simultaneous determination of frequency-dependent and dynamic characteristics of materials no efficient methods and test stands are known. The measurement of the dependent properties at different frequencies requires plenty of measuring time as well as very high manpower-related costs, therefore, it is rarely performed. The approach presented in this paper, that is an experimental measurement combined with a theoretical investigation sequence enables the engineer to efficiently determine dynamic properties of the rubber material and a composite material based on rubber and frequency data at the design stage. The research based on the investigation of composite pipeline characteristics will be done in future through simulation of pipeline deformation in working conditions. The present research is directed into investigation of values of damping and stiffness coefficients aiming at a rheological model of the composite pipeline with taking in account the frequency response of the material.

\section{Object of research}

A high-pressure hose $(\mathrm{HPH})$ is a flexible pipeline designed to transmit hydraulic forces and a working fluid between units of a hydraulic drive system. Usually, HPHs in hydraulic drive systems are made of a few different layers which include rubber and a fabric braid Fig. 2a (Cho, 2017) or a metal braid Fig. 2b (Pelevin et al., 2016). This type of pipelines is commonly used in different hydraulic drive systems and constitute an extensive system with hundreds of different types of HPHs in one application Fig. 2c (Karpenko and Bogdevičius, 2020).

The primary reason why objects have significant displacement and vibration response by load, it is the material what are they made of. The material of pipelines belongs to the com- 
(a)

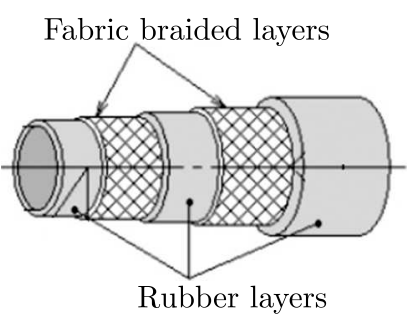

(b)

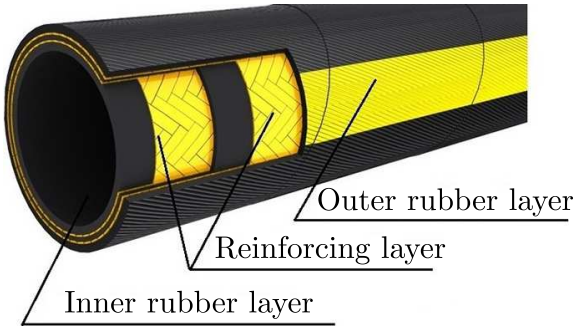

(c)

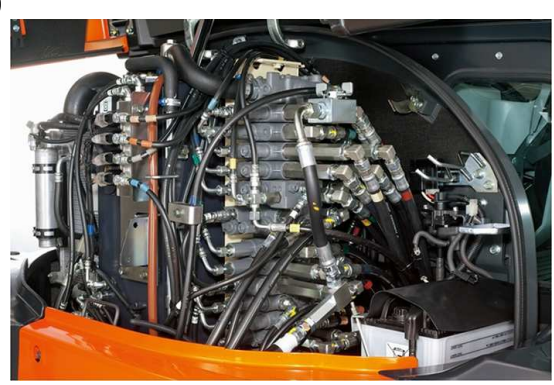

Fig. 2. Typical hydraulic composition of the system: (a) view of a textile-braided pipeline (Cho, 2016),

(b) view of a metal braided pipeline (Pelevin et al., 2016), (c) part of the hydraulic system with a manipulator (Karpenko and Bogdevičius, 2020)

posite class of substances that show viscous-elastic properties responding to external forces in an intermediate manner between the behaviour of an elastic solid and a viscous liquid. Shaw and MacKnight (2005) attributted to the material an instantaneous elastic strain together with a retarded damping effect. Furthermore, Duan et al. (2010) demonstrated that the visco-elastic effects are deeply more significant when the retardation time is less than the time of wave travelling along the entire pipeline length. Approximate coefficients of elasticity and shear elasticity as well as the procedure for their determination for composite pipelines are presented in work Molnár et al. (1990). To reproduce the real behaviour of the pipeline material, it is necessary to introduce a viscous-elastic model. A constitutive relation of linear viscous-elasticity is built up, considering the material as a sum of linear elements such as (elastic) linear springs and (viscous) linear dashpots to take into account also the time-dependent relaxation of the wall.

The simplest model able to correctly reproduce the stress-strain behaviour of a composite material is a 3-parameter model known as the Standard Linear Solid Model (SLSM), which can be structured with a Maxwell or a Kelvin-Voigt element according to Bertaglia et al. (2018). The schematic representations of both types of the models are shown in Fig. 3, see Bertaglia et al. (2018).
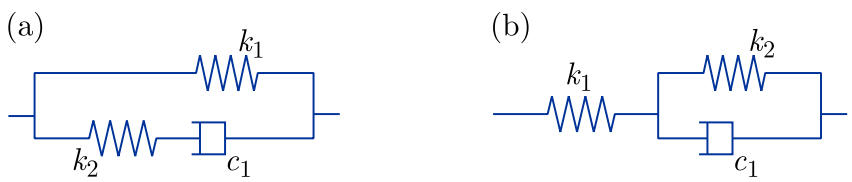

Fig. 3. Schemes of the 3-parameter SLSM by Bertaglia et al. (2018): (a) Maxwell element,

(b) Kelvin-Voigt element

To obtain more flexible models, it is possible to extend the chain of Maxwell or Kelvin-Voigt elements to an infinite number. Theoretically, the more elements we have, the more accurate our model will be in describing the real response of the material. From Bertaglia et al. (2018) and a review of all previous research, it can be easily observed that none of them takes into account detailed investigation of coefficients of viscous-elastic models and, in this case, it is not possible to completely describe deformation and damping behaviour of the material and to take into account the frequency response of the materials. It confirms that all the parameters that influence the viscous-elastic effects must be determined in order to obtain realistic solutions.

\section{Pre-experiment investigation}

In the pre-experiment investigation, a piece of pipeline (ISO 4079:2017) with a high strength braided textile was used. The dimensions of the cut out piece are $35 \times 15 \times 6[\mathrm{~mm}]$. The inves- 
tigated material is a composite (layers number $n$ equal to 3) with the inner layer - synthetic rubber (NBR), outer layer - anti-abrasive synthetic rubber (NBR/PVC), reinforcing layer synthetic rubber (NBR) reinforced with a high strength braided textile. The top mass is made of steel with dimensions $\emptyset 55 \times 25[\mathrm{~mm}]$ and mass of the load $-0.5 \mathrm{~kg}$. The description of physical and geometrical parameters of the investigated objects is present in Table 1.

Table 1. Physical and geometrical parameters of investigated objects

\begin{tabular}{|c|c|c|c|c|c|}
\hline Object & $\begin{array}{c}\text { Dimension } \\
{[\mathrm{mm}]}\end{array}$ & $\begin{array}{c}\text { Tensile } \\
\text { strength }[\mathrm{MPa}]\end{array}$ & $\begin{array}{c}\text { Mass } \\
{[\mathrm{kg}]}\end{array}$ & $\begin{array}{c}\text { Density } \\
{\left[\mathrm{kg} / \mathrm{m}^{3}\right]}\end{array}$ & $\begin{array}{c}\text { Number of } \\
\text { layers } n\end{array}$ \\
\hline \hline Pipeline material & $35 \times 15 \times 6$ & 24.1 & $4.2 \cdot 10^{-3}$ & 1350 & 3 \\
\hline Top (load) mass & $\emptyset 55 \times 25$ & 420 & 0.5 & 8050 & 1 \\
\hline
\end{tabular}

An experimental bench for the pre-experiment spectral analysis is shown in Fig. 4 and includes: 1 - Polytec vibrometer controller OFV-5000, 2 - PSV zensor head, 3 - IEPE impulse hammer, 4 - research surface, 5 - metal base, 6 - HPHs layer, 7 - top mass.
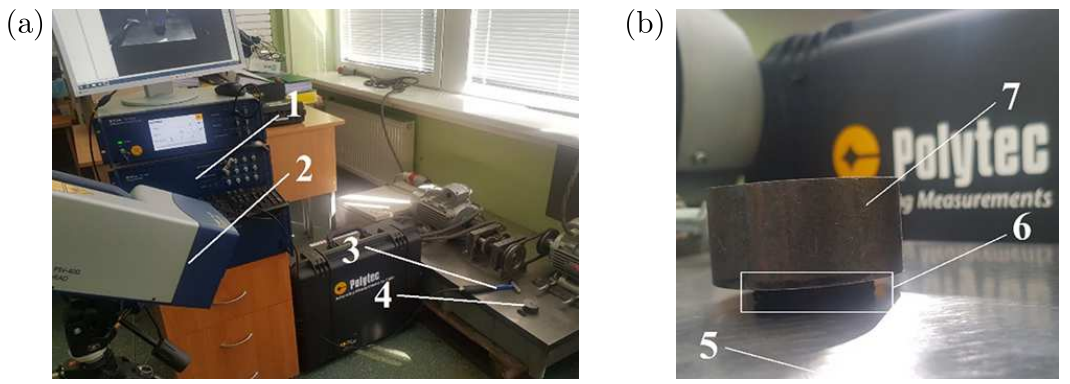

Fig. 4. The experimental bench for spectral analysis of the composite material of the pipeline: (a) view of experimental bench, (b) research object with the top mass; 1 - vibrometer controller OFV-5000,

2 - PSV sensor head, 3 - IEPE impulse hammer, 4 - research surface and objects, 5 - metal base, 6 - HPHs layer, 7 - top mass

The experiment includes several measurements of displacement, speed and acceleration on the top mass of the investigated object. To minimize errors due to not an equal force of the impact from the impulse hammer in each measurement, average results of several measurements were accepted. The time of a single measurement by PSV sensor head amounts to 4 seconds during which, between $2 \mathrm{~s}$ and $3 \mathrm{~s}$, the IEPE impulse hammer generates an impulse on the metal base with a force shown in Fig. 5a, and the velocity measured by PSV sensor head on the metal base shown in Fig. 5b.

The velocity measured by the PSV sensor head on the top mass is shown in Fig. 6. In Fig. 6a it is shown for all the test time, and in Fig. $6 \mathrm{~b}$ for the time from $2.23 \mathrm{~s}$ to $2.265 \mathrm{~s}$ (during the impulse generated by the IEPE hammer).

AS a result of spectral analysis, frequency response to velocity variation is shown in Fig. 7a (until $1.6 \mathrm{kHz}$ ), and in Fig. $7 \mathrm{~b}$ there is a frequency response to a change in velocity up to $500 \mathrm{~Hz}$.

From the obtained experimental results it seems that the viscous-elastic properties of the composite pipe material reduces a pick of the velocity impulse, from the IEPE impulse hammer, from $6.74 \cdot 10^{-5} \mathrm{~m} / \mathrm{s}$ (Fig. 5b) to $7.69 \cdot 10^{-7} \mathrm{~m} / \mathrm{s}$ (Fig. 6b), which confirms damping properties of the composite pipeline material. The main result has been obtained from the experimental part - the frequency response based on the spectral analysis using the Doppler effect. From the frequency analysis, see Fig. 7a, it seems that the main resonance frequency of the pipe composite material is in the low frequency $(0 \mathrm{~Hz}-200 \mathrm{~Hz})$ and at th beginning of the middle frequency $(200 \mathrm{~Hz}-5 \mathrm{kHz})$. It should be noted that the main interest of the research is the frequency range up to $1000 \mathrm{~Hz}$. In this frequency range, we can observe the main resonant modes. From the frequency 
(a)

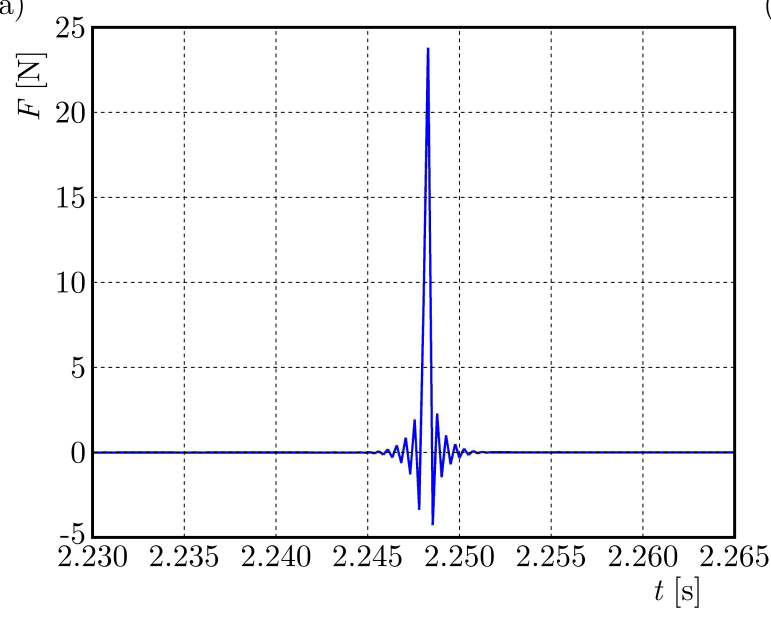

(b)

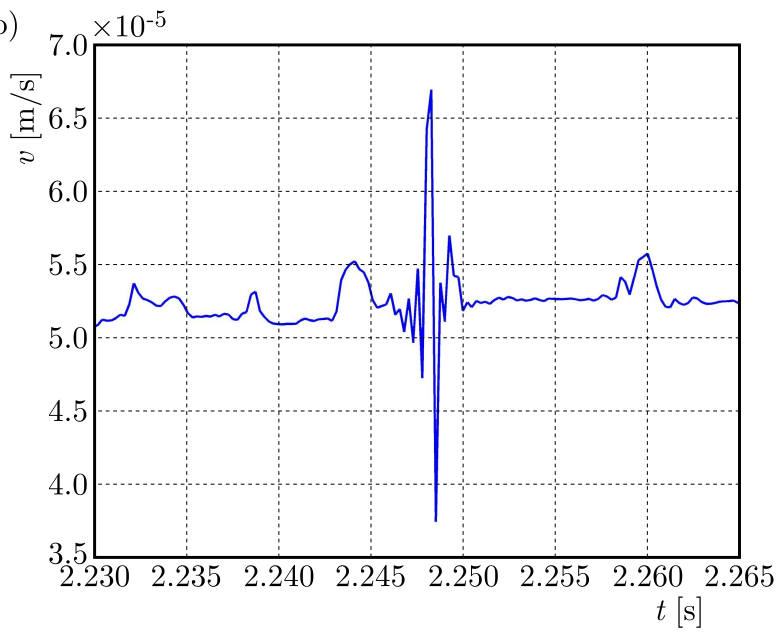

Fig. 5. Graphs of pre-experimental measuring (1/3): (a) signal from the IEPE impulse hammer, (b) velocity from the PSV sensor head on the metal base
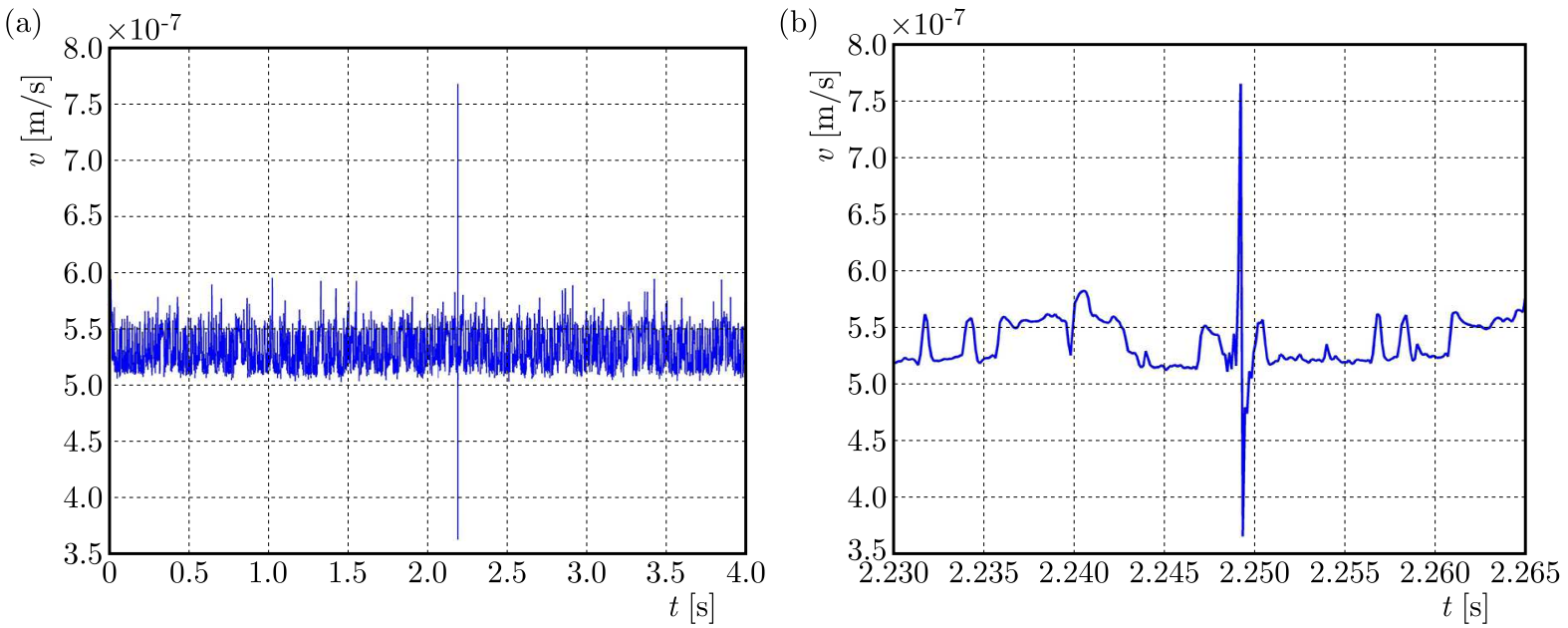

Fig. 6. Graphs of pre-experimental measuring (2/3): (a) velocity from the PSV sensor head on the top mass during all the test time, (b) velocity from the PSV sensor head on the top mass during the time from $2.23 \mathrm{~s}$ to $2.265 \mathrm{~s}$ (when the IEPE impulse is generated)

(a)

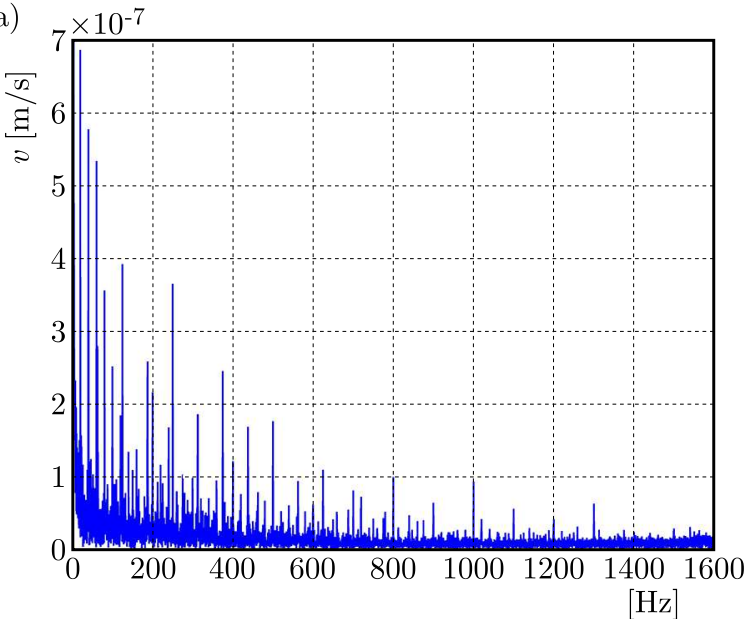

(b)

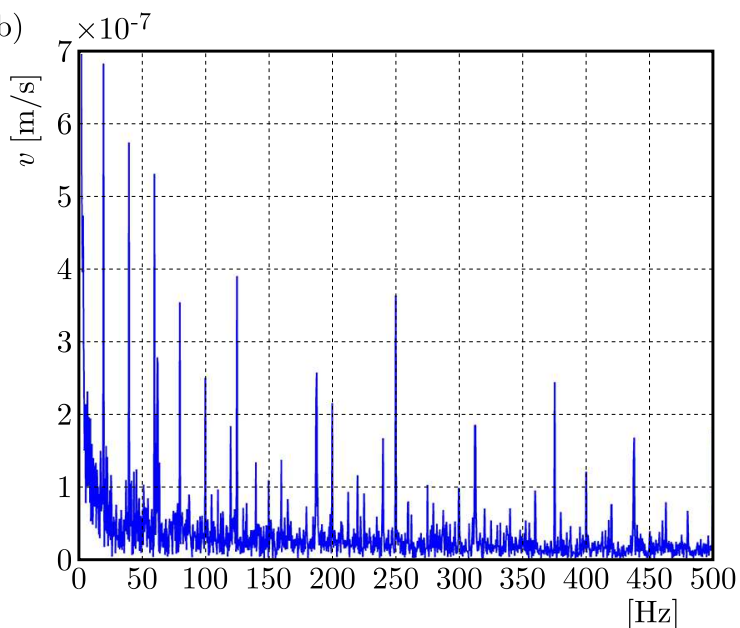

Fig. 7. Graphs of pre-experimental measuring (3/3): (a) frequency response to velocity variation up to $1.6 \mathrm{kHz}$, (b) frequency response up to $500 \mathrm{~Hz}$ 
analysis, it seems that the main and first resonance frequency of the investigated composite material is equal to $20 \mathrm{~Hz}$ with harmonics by every $20 \mathrm{~Hz}(20 / 40, \ldots, 80 / 100, \ldots$, etc. $\mathrm{Hz})$. Worth noticing are low range frequencies $37.5 \mathrm{~Hz}$ and $67.5 \mathrm{~Hz}$ and then from $157.5 \mathrm{~Hz}$ and $187.5 \mathrm{~Hz}$ (Fig. $7 \mathrm{~b}$ ) with a step by $30 \mathrm{~Hz}$ what is continued in the middle range frequency. The existence of the second resonance frequency can be explained by the composite nature of the investigation object.

\section{Mathematical model}

The main idea of the research and the mathematical model is that the investigated material is divided into $n$ masses (from $m_{1}$ to $m_{n}$ ) with the top mass $m_{n+1}$ (Fig. 8a). Thickness of each element $\Delta$ is individual and depends on the researcher's decision and thickness of the composite layers. The scheme of distributed forces and displacements between the masses as well as position of elements of the proposed mathematical model is shown in Fig. 8b. The schemes in Fig. 8 show general cases when the material can be devided into any number of $n$ masses.

(a)

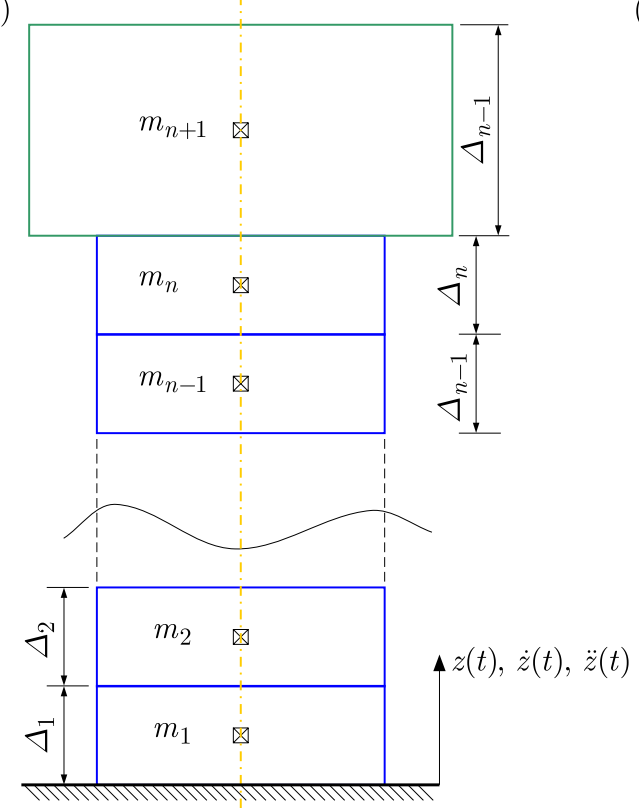

(b)

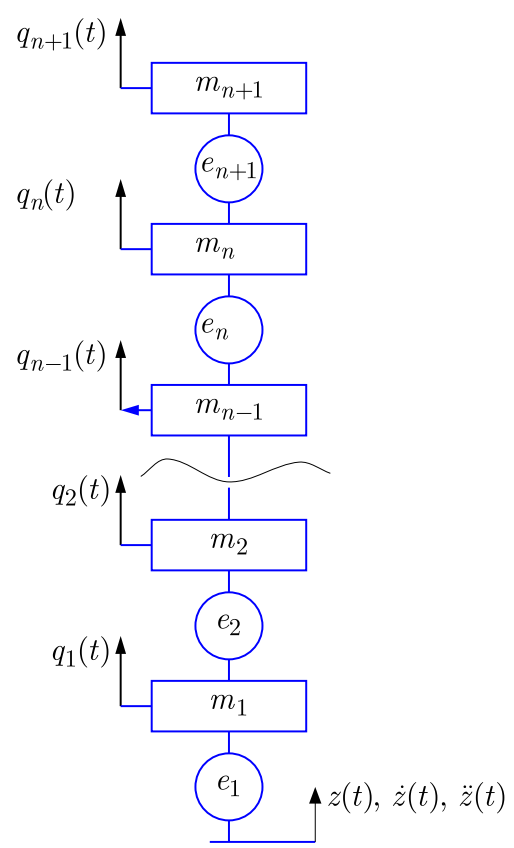

Fig. 8. Scheme of the calculation mathematical model: (a) principal scheme of the material with $n$ masses and the load mass, (b) scheme of forces and displacements between the elements

The material in the pre-experiment test is divided into $n=3$ masses with the load mass $n+1$ on the top investigated like a solid body. The research enabled determination of parameters of elements of the rheological model. According to pre-experimental investigation, the impulse is generated from the bottom of the model and then transferred through elements to the top load. For the first force, the equation of the model is used to find values of the displacement $z$, velocity $\dot{z}$ and acceleration $\ddot{z}$ of the impulse from the IEPE impulse hammer in the pre-experimental investigation.

Each element from $e_{1}$ to $e_{n+1}$ of the mathematical model represents a hybrid Maxwell and Kelvin-Voigt rheological model. In Fig. 9, elements of the rheological model are shown where $k_{i}$ and $c_{i}$ are stiffness and damping coefficients, respectively, and $q_{i}$ are displacements between the rheological elements. In the proposed five-parameter rheological model not only the displacements are unknown, but also the forces that are described by second-order differential equations. 


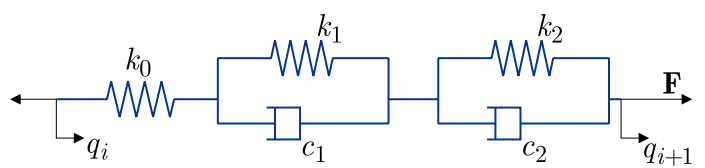

Fig. 9. Elements of the rheological model

The range of the minimum and maximum values of the coefficients in the optimization task are given in Table 2 . The initial value of the rheological coefficients are proposed to be in between the max and min limits, see Table 2.

Table 2. Values of the proposed rheological model coefficients

\begin{tabular}{|c|c|c|c|}
\hline Coefficient [unit] & Min & Max & Initial value for modelling \\
\hline \hline$k_{0}[\mathrm{~N} / \mathrm{m}]$ & $1.0 \cdot 10^{8}$ & $2.5 \cdot 10^{9}$ & $1.3 \cdot 10^{9}$ \\
\hline$k_{1}[\mathrm{~N} / \mathrm{m}]$ & $1.0 \cdot 10^{7}$ & $1.0 \cdot 10^{9}$ & $5.05 \cdot 10^{8}$ \\
\hline$c_{1}[\mathrm{Ns} / \mathrm{m}]$ & $1.0 \cdot 10^{6}$ & $2.0 \cdot 10^{8}$ & $1.005 \cdot 10^{8}$ \\
\hline$k_{2}[\mathrm{~N} / \mathrm{m}]$ & $1.0 \cdot 10^{7}$ & $1.0 \cdot 10^{9}$ & $5.05 \cdot 10^{8}$ \\
\hline$c_{2}[\mathrm{Ns} / \mathrm{m}]$ & $1.0 \cdot 10^{7}$ & $1.0 \cdot 10^{9}$ & $5.05 \cdot 10^{8}$ \\
\hline
\end{tabular}

According to the mathematical model, the system of equations for each mass is as follows

$$
\begin{aligned}
& m_{1} \ddot{q}_{1}=-F_{0,1}+F_{1,2}-m_{1} g \\
& m_{2} \ddot{q}_{2}=-F_{1,2}+F_{2,3}-m_{2} g \\
& \vdots \\
& m_{n} \ddot{q}_{n}=-F_{n-1, n}+F_{n, n+1}-m_{n} g \\
& m_{n+1} \ddot{q}_{n+1}=-F_{n, n+1}-m_{n+1} g
\end{aligned}
$$

where $F_{i, i+1}$ is the force between neighbouring elements, $g$ - the standard gravity defined as $9.80665 \mathrm{~m} / \mathrm{s}^{2}$.

Each force between the neighbouring elements can be described by the formulas

$$
\begin{aligned}
& \ddot{F}_{0,1}+a_{10,1} \dot{F}_{0,1}+a_{10,1} F_{0,1}=b_{10,0}\left(q_{1}-z\right)+b_{10,1}\left(\dot{q}_{1}-\dot{z}\right)+b_{10,2}\left(\ddot{q}_{1}-\ddot{z}\right) \\
& \ddot{F}_{1,2}+a_{12,1} \dot{F}_{1,2}+a_{12,0} F_{1,2}-b_{12,0}\left(q_{2}-q_{1}\right)-b_{12,1}\left(\dot{q}_{2}-\dot{q}_{1}\right)-b_{12,2}\left(\ddot{q}_{2}-\ddot{q}_{1}\right)=0 \\
& \vdots \\
& \ddot{F}_{n-1, n}+a_{n, 1} \dot{F}_{n-1, n}+a_{n, 0} F_{n-1, n}-b_{n, 0}\left(q_{n}-q_{n-1}\right)-b_{n, 1}\left(\dot{q}_{n}-\dot{q}_{n-1}\right)-b_{n, 2}\left(\ddot{q}_{n}-\ddot{q}_{n-1}\right)=0 \\
& \quad \ddot{F}_{n, n+1}+a_{n+1,1} \dot{F}_{n, n+1}+a_{n+1,0} F_{n, n+1}-b_{n+1,0}\left(q_{n+1}-q_{n}\right)-b_{n+1,1}\left(\dot{q}_{n+1}-\dot{q}_{n}\right) \\
& \quad-b_{n+1,2}\left(\ddot{q}_{n+1}-\ddot{q}_{n}\right)=0
\end{aligned}
$$

The coefficients near variables in the force equation are described by the following relationships

$$
\begin{aligned}
& a_{i, 0}=\frac{k_{0} k_{1}+k_{0} k_{2}+k_{1} k_{2}}{c_{1} c_{2}} \quad a_{i, 1}=\frac{c_{1} k_{0}+c_{1} k_{2}+c_{2} k_{0}+c_{2} k_{1}}{c_{1} c_{2}} \\
& b_{i, 0}=\frac{k_{0} k_{1} k_{2}}{c_{1} c_{2}} \quad b_{i, 1}=\frac{c_{1} k_{0} k_{2}+c_{2} k_{0} k_{1}}{c_{1} c_{2}} \quad b_{i, 2}=k_{0}
\end{aligned}
$$

In the first equation of the force from the base to the first mass we have certain values of the displacement $z$, velocity $\dot{z}$ and acceleration $\ddot{z}$ of the impulse from the IEPE impulse hammer. Moving all unknowns to the left-hand side of the force equation and certain variables to the right-hand side, we get the equation

$$
\ddot{F}_{0,1}+a_{10,1} \dot{F}_{0,1}+a_{10,1} F_{0,1}-b_{10,0} q_{1}-b_{10,1} \dot{q}_{1}-b_{10,2} \ddot{q}_{1}=-b_{10,0} z-b_{10,1} \dot{z}-{ }_{10,2} \ddot{z}
$$


The systems of equations (4.1) and (4.2) can be joined in a single dynamical equation

$$
\mathbf{M X}+\mathbf{C X}+\mathbf{K X}=\mathbf{F}(t)
$$

where $\mathbf{M}, \mathbf{C}$ and $\mathbf{K}$ are inertia, damping and stiffness matrices, respectively. The matrices $\mathbf{M}$, $\mathbf{C}$ and $\mathbf{K}$ are non-symmetrical and have the following form

$$
\begin{aligned}
\mathbf{M} & =\left[\begin{array}{ccccccccc}
m_{1} & 0 & 0 & 0 & \cdots & 0 & 0 & 0 & 0 \\
-b_{10,2} & 1 & 0 & 0 & \cdots & 0 & 0 & 0 & 0 \\
0 & 0 & m_{2} & 0 & \cdots & 0 & 0 & 0 & 0 \\
b_{12,2} & 0 & -b_{12,2} & 1 & \cdots & 0 & 0 & 0 & 0 \\
\vdots & \vdots & \vdots & \vdots & \ddots & \vdots & \vdots & \vdots & \vdots \\
0 & 0 & 0 & 0 & \cdots & m_{n} & 0 & 0 & 0 \\
0 & 0 & 0 & 0 & \cdots & -b_{n, 2} & 1 & 0 & 0 \\
0 & 0 & 0 & 0 & \cdots & 0 & 0 & m_{n+1} & 0 \\
0 & 0 & 0 & 0 & \cdots & b_{n+1,2} & 0 & -b_{n+1,2} & 1
\end{array}\right] \\
\mathbf{C} & =\left[\begin{array}{ccccccccc}
0 & 0 & 0 & 0 & \cdots & 0 & 0 & 0 & 0 \\
-b_{10,1} & a_{10,1} & 0 & 0 & \cdots & 0 & 0 & 0 & 0 \\
0 & 0 & 0 & 0 & \cdots & 0 & 0 & 0 & 0 \\
b_{12,1} & 0 & -b_{12,1} & a_{12,1} & \cdots & 0 & 0 & 0 & 0 \\
\vdots & \vdots & \vdots & \vdots & \ddots & \vdots & \vdots & \vdots & \vdots \\
0 & 0 & 0 & 0 & \cdots & 0 & 0 & 0 & 0 \\
0 & 0 & 0 & 0 & \cdots & -b_{n, 1} & a_{n, 1} & 0 & 0 \\
0 & 0 & 0 & 0 & \cdots & 0 & 0 & 0 & 0 \\
0 & 0 & 0 & 0 & \cdots & b_{n+1,1} & 0 & -b_{n+1,1} & a_{n+1,1}
\end{array}\right] \\
\mathbf{K} & =\left[\begin{array}{cccccccccc}
0 \\
0 & 1 & 0 & 0 & \cdots & 0 & 0 & 0 & 0 \\
-b_{10,0} & a_{10,0} & 0 & 0 & \cdots & 0 & 0 & 0 & 0 \\
0 & -1 & 0 & 1 & \cdots & 0 & 0 & 0 & 0 \\
b_{12,0} & 0 & -b_{12,0} & a_{12,0} & \cdots & 0 & 0 & 0 & 0 \\
\vdots & \vdots & \vdots & \vdots & \ddots & \vdots & \vdots & \vdots & \vdots \\
0 & 0 & 0 & 0 & \cdots & 0 & 1 & 0 & -1 \\
0 & 0 & 0 & 0 & \cdots & -b_{n, 0} & a_{n, 0} & 0 & 0 \\
0 & 0 & 0 & 0 & \cdots & 0 & 0 & 0 & 1 \\
0 & 0 & 0 & 0 & \cdots & b_{n+1,0} & 0 & -b_{n+1,0} & a_{n+1,0}
\end{array}\right]
\end{aligned}
$$

The vector $\mathbf{X}$ of variables and the vector $\mathbf{F}(t)$ of forces are as follows

$$
\begin{aligned}
& \mathbf{X}^{\mathrm{T}}=\left[q_{1}, F_{0}, 1, q_{2}, F_{1}, 2, \ldots, q_{n}, F_{n-1, n}, q_{n+1}, F_{n, n+1}\right] \\
& \mathbf{F}(t)^{\mathrm{T}}=\left[-m_{1} g,-b_{10,0} z-b_{10,1} \dot{z}-b_{10,2} \ddot{z},-m_{2} g, 0, \ldots,-m_{n} g, 0,-m_{n+1} g, 0\right]
\end{aligned}
$$

For closer determination of coefficient values of the rheological elements, an optimization task according to Bogdevičius et al. (2016) has been generated. First of all, a vector of unknowns p for each element of the rheological model has been introduced

$$
\mathbf{p}^{\mathrm{T}}=\left[k_{0}, k_{1}, c_{1}, k_{2}, c_{2}\right]
$$

after which these unknowns were normalized using the expression

$$
S_{i}=\frac{p_{i}-p_{i \min }}{p_{\text {imax }}-p_{\text {imin }}}
$$


where $p_{i \max }$ and $p_{i \min }$ are the maximal and minimal values of the corresponding parameter of the $i$-th unknown vector.

To get the vector $\mathbf{S}$ (where each $S_{i}$ of the unknowns comes from (4.9))

$$
\mathbf{S}^{\mathrm{T}}=\left[S_{1}, \ldots, S_{5}\right]
$$

Then a target optimization function to optimize the difference between the normalized amplitudes obtained experimentally and theoretically has been formulated. Let us now sum the resonant amplitudes and compose the objective function

$$
\min \Phi=\sum_{j=1}^{N H}\left(\frac{A_{j}\left(f_{j}, S\right)-A_{j \exp }\left(f_{j}\right)}{A_{0}}\right)^{2}
$$

where $N H$ is the number of frequencies at which the amplitude difference is minimized. To compose the objective function, it is necessary that the difference of each term of the objective function changes in a minimal range. That is why the amplitudes in the given objective function are also normalized. In this case, the optimization problem will be posed correctly and the solution time will be shorter. The amplitude $A_{j}$ for the theoretical and $A_{j} \exp$ for the experimental results is divided by the constant amplitude $A_{0}$.

The frequency steps in the experimental and theoretical studies do not coincide, the experimental amplitude for equation (4.11) at the frequency $f_{j}$ should be clarified by the expression

$$
A_{j \exp }\left(f_{j}\right)=\frac{f_{k+1}-f_{j}}{f_{k+1}-f_{k}} A_{k}\left(f_{k}\right)+\frac{f_{j}-f_{k}}{f_{k+1}-f_{k}} A_{k+1}\left(f_{k+1}\right)
$$

In each iteration, a new spectrum of the velocity amplitude $A_{j}$ is obtained. The frequency $f_{j}$ is determined in the interval between $f_{k}$ and $f_{k+1}$ of the experimental measurement data.

To determine the theoretical amplitudes at corresponding frequencies, a system of equations (4.5) have to be solved during $0 \leqslant t \leqslant T$ ( $T$ - solution time). The algorithm of the optimization task is shown in Fig. 10.

After making use of the that using Fourier analysis, theoretical frequencies and spectra of theoretical oscillations are obtained. From the obtained spectra, the frequencies at which the function has been normalized were determined which refined the coefficients that stand for the entire function. The proposed mathematical model is represented by five rheological parameters and includes an optimization task help one to determine stiffness and damping coefficients of rubber (rubber matrix composite) elements. The achieved result will help prospecting computational modeling of composite materials based on rubber with taking into account the contact problem of the layers and their reinforcement behavior.

\section{Results}

Values of the objective function in each iteration shown in Fig. 11 as well as dimensionless optimization parameters depend on the iteration shown in Fig. 12. The obtained results show that at the initial iteration the objective function is in the high range. The solution of optimization continues until the objective function reaches the tolerance Toler $=10^{-4}$. After 120 iterations, the objective function reaches the tolerance. The solution time $T$ according to the experiment is equal to $4 \mathrm{~s}$.

Differences in velocity amplitudes versus frequencies between experimental measurements and theoretical modelling are shown in Fig. 13.

In Table 3 values of the proposed rheological coefficients after optimization are presented. 


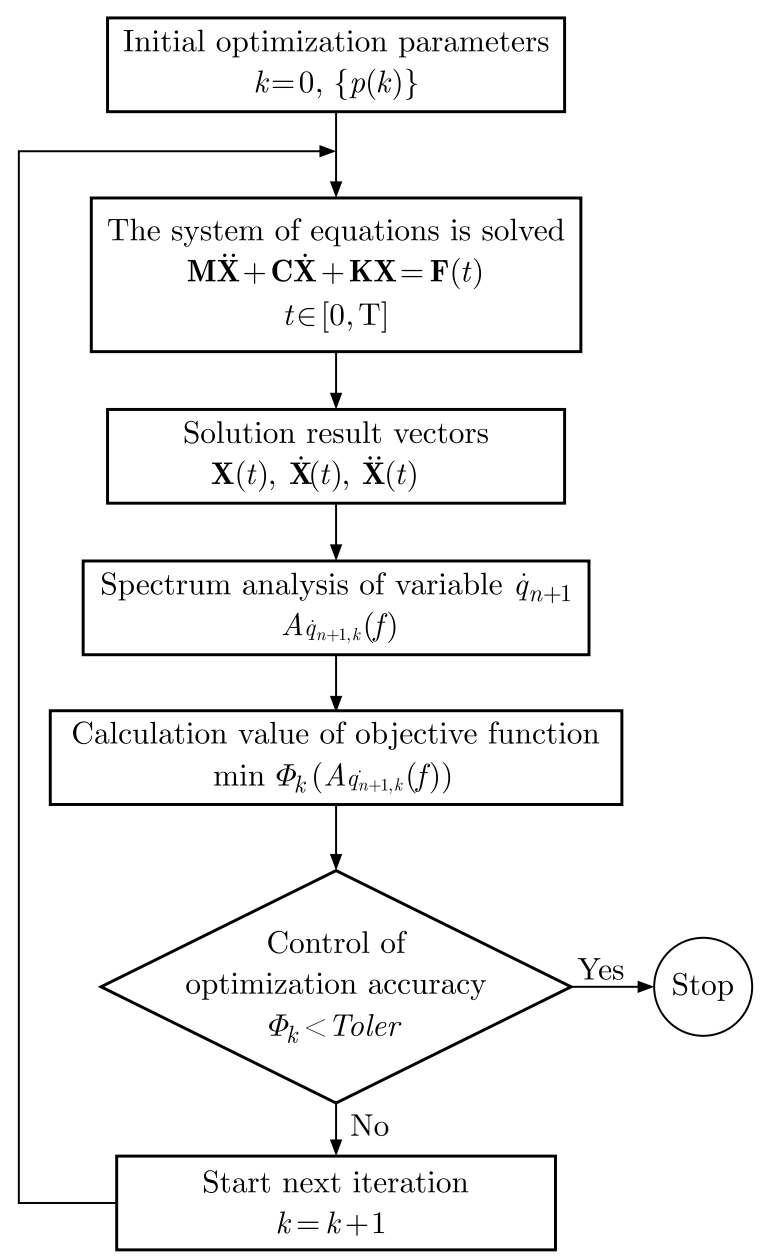

Fig. 10. The algorithm of the optimization task

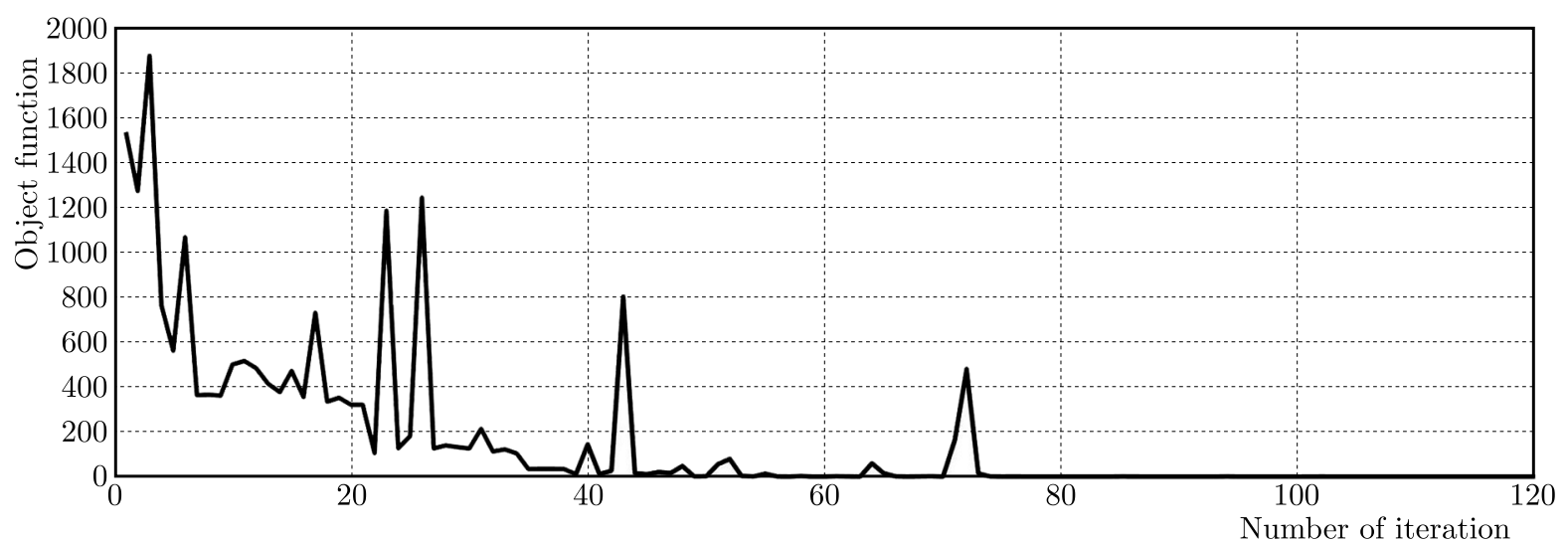

Fig. 11. Graph of the dependence of the objective function on iterations

The difference in the frequency response between experimental measurements and theoretical modelling is less than $<2 \%$ for greater frequencies (see Fig. 13a). It should be pointed out that the difference in the resonances does not exceed 1\%. From the logarithm spectrum of the velocity amplitude (Fig. 13b), it can be noted that still in some frequencies after optimization the difference in the amplitude is significant, but the numbers of such frequencies is diminishing. The conducted research discloses that the coefficients of the rheological model of the composite pipeline can be easily determined in future modelling by spectral analyses and optimization of 


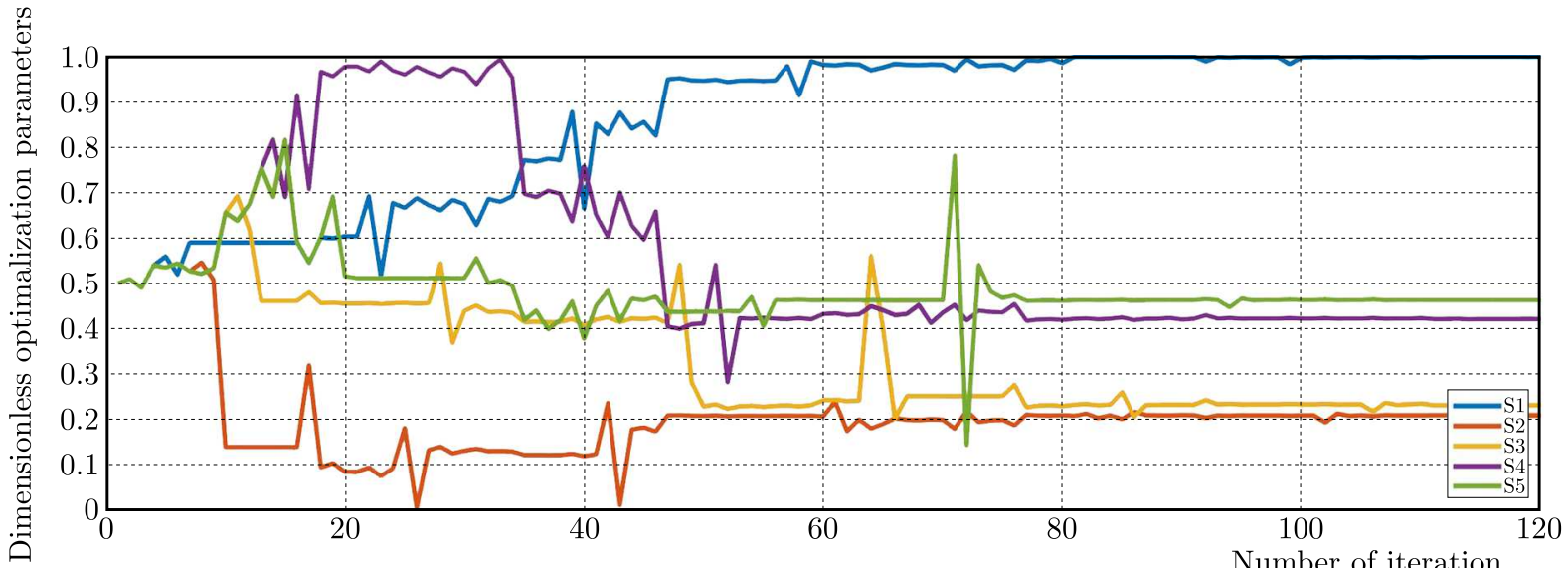

Fig. 12. Graph of the dependence of dimensionless optimization parameters on iterations
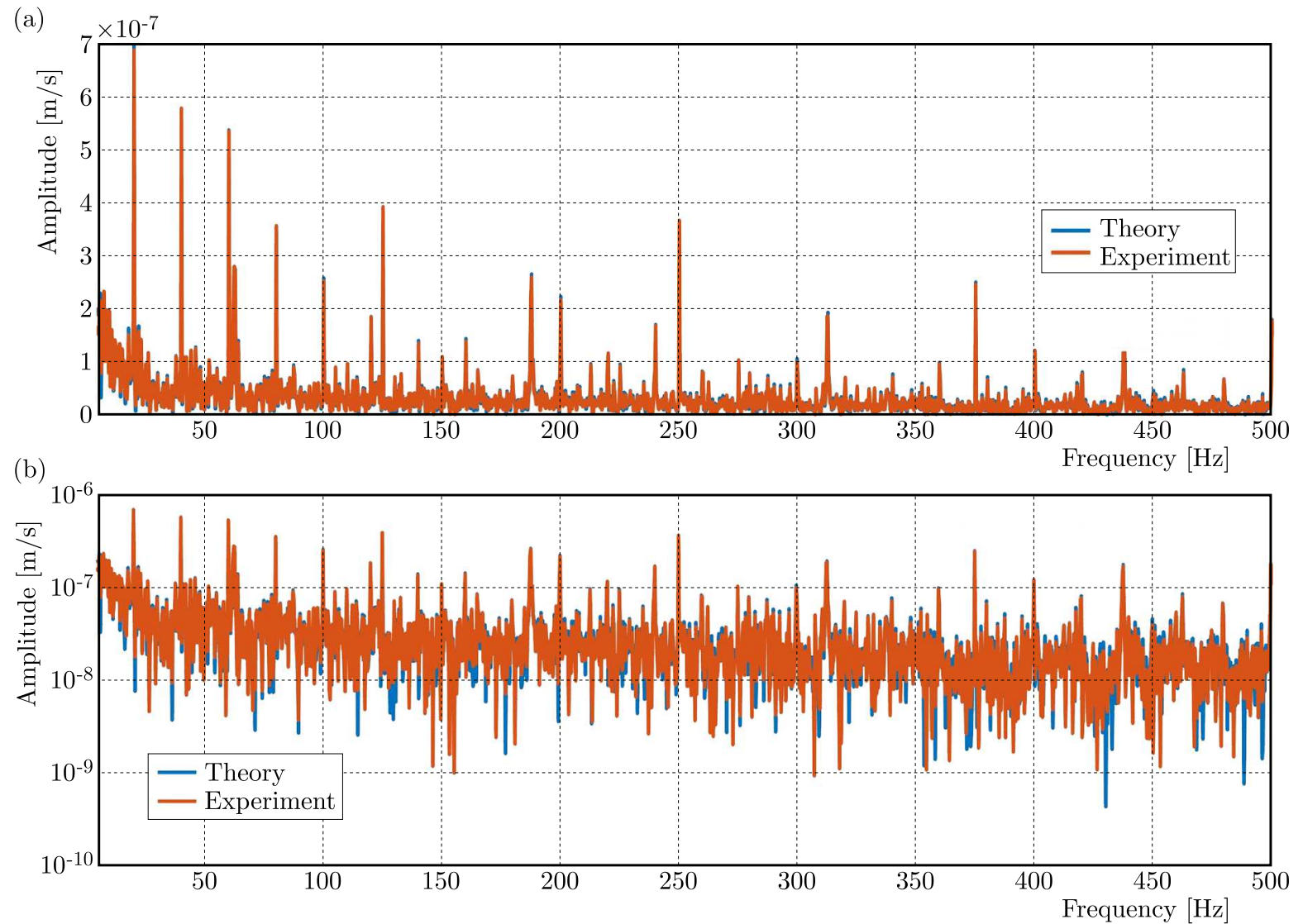

Fig. 13. Graphs of comparisons of the frequency response between experimental and theoretical investigations: (a) spectrum of the velocity amplitude, (b) logarithm spectrum of the velocity amplitude

Table 3. Value of the rheological model coefficients after optimization

\begin{tabular}{|c|c|}
\hline Coefficient [unit] & Value \\
\hline \hline$k_{0}[\mathrm{~N} / \mathrm{m}]$ & $2.4986 \cdot 10^{9}$ \\
\hline$k_{1}[\mathrm{~N} / \mathrm{m}]$ & $2.1749 \cdot 10^{8}$ \\
\hline$c_{1}[\mathrm{Ns} / \mathrm{m}]$ & $4.7148 \cdot 10^{7}$ \\
\hline$k_{2}[\mathrm{~N} / \mathrm{m}]$ & $4.2709 \cdot 10^{8}$ \\
\hline$c_{2}[\mathrm{Ns} / \mathrm{m}]$ & $4.6837 \cdot 10^{8}$ \\
\hline
\end{tabular}


the present mathematical model relying on the frequency response. The present research might be useful for future research in the area of composite pipelines, by taking into account viscoelastic properties of materials to obtain realistic models and simulation dynamic processes inside the composite material (internal friction, pipeline deformation under loading, etc.).

\section{Conclusion}

With reference to the theoretical research on determination of coefficients of the proposed rheological elements (five-parameter hybrid Maxwell and Kelvin-Voigt rheological model) of the pipeline material the obtained results show that the proposed methodology well describes viscous-elastic properties of the composite material based on rubber. In the proposed rheological model not only the displacements are unknown, but also the forces that are described by second-order differential equations. From experimental measurements, it occurs that the pick of the velocity impulse is reduced from $6.74 \cdot 10^{-5} \mathrm{~m} / \mathrm{s}$ (on the metal base) down to $7.69 \cdot 10^{-7} \mathrm{~m} / \mathrm{s}$ (on the top mass), which confirms damping properties of the pipeline material. Spectral analysis proves that the main resonance frequencies are in the low frequency $(0-200 \mathrm{~Hz})$ range and near the beginning of the middle frequency $(200 \mathrm{~Hz}-5 \mathrm{kHz})$. The main resonance frequency of the investigate composite material is equal to $20 \mathrm{~Hz}$ with harmonics by every $20 \mathrm{~Hz}(20 / 40, \ldots, 80 / 100, \ldots \mathrm{Hz})$. In the low frequency range from $37.5 \mathrm{~Hz}$ to $67.5 \mathrm{~Hz}$ and then from $157.5 \mathrm{~Hz}$ to $187.5 \mathrm{~Hz}$ the resonance appears with a step of $30 \mathrm{~Hz}$, what is continued in the middle range of frequencies. The existence of the second resonance can be explained by the composite nature of the investigated object. The proposed mathematical model after optimization helps one to determine coefficients of the rheological elements for the obtained experimental results relying on the frequency response. The optimization takes around 120 iterations for the objective function to reach the specified tolerance. Verification of the obtained values has been carried out by comparing the frequency responses from experimental and theoretical investigations. The difference of between the amplitudes from experimental measurements and theoretical modelling are less then $<2 \%$ for greater frequencies. The present research might be helpful for future studies in the area of composite pipelines with taking into account visco-elastic properties of rubber to obtain a realistic model and possibility of simulation of dynamic processes inside the composite material (internal friction, pipeline deformation under loading, etc.). The achieved findings may support future computational modeling of composite materials based on rubber with taking into account the contact and reinforcement problem of the layers. The proposed methodology can be used for dynamical analysis of rubber in composite materials to determine mechanical characteristics and for future use in computational modelling with application of discrete lattice elements.

\section{Acknowledgement}

The research work has been supported by the Research Council of Lithuania Fund within the project "Investigation of tribological micro-macro processes in multi-phase layer with ice-snow particles and their contribution to tire-layer-surface system", project code P-MIP-17-233.

\section{References}

1. Abe A., Kamegawa T., Nakajima Y., 2004, Optimization of construction of tire reinforcement by genetic algorithm, Optimization and Engineering, 5, 77-92

2. Avril S., Bonnet M., Bretelle A., Grédiac M., Hild F., Ienny P., Latourte F., Lemosse D., Pagano S., Pagnacco E., Pierron F., 2008, Overview of identification methods of mechanical parameters based on full-field measurements, Experimental Mechanics, 48, 381 
3. Baranowski P., Janiszewski J., MaŁachowski J., 2017, Tire rubber testing procedure over a wide range of strain rates, Journal of Theoretical and Applied Mechanics, 55, 2, 727-739

4. Baranowski P., MaŁachowski J., Mazurkiewicz Ł., 2020, Local blast wave interaction with tire structure, Defence Technology, 16, 3, 520-529

5. Bertaglia G., Ioriatti M., Valiani A., Dumbser M., Caleffi V., 2018, Numerical methods for hydraulic transients in visco-elastic pipes, Journal of Fluids and Structures, 81, 230-254

6. Bogdevičius P., Prentkovskis O., Bogdevičıus M., 2017, Influence of the Cardan joint on characteristics of a centrifugal pump in a transmission system (in Lithuanian), Mokslas - Lietuvos Ateitis/Science - Future of Lithuania, 9, 5, 559-564

7. Bogdevičius M., Prentkovskis O., Junevičıus R., Skrickij V., Šukevičius Š., 2016, Behavior and optimization of pneumatic damping system, Iranian Journal of Science and Technology, Transactions of Mechanical Engineering, 40, 2

8. Bogdevičius M., Ružinskas A., Vadlūga V., Bogdevičius P., KaČianauskas R., Maknickas A., Gauterin F., 2019, Investigation of tire force transmission on interaction with slush, Problemy Transportu - Transport Problems, 14, 1, 13-21

9. Сно J., 2017, Anisotropic large deformation and fatigue damage of rubber-fabric braid layered composite hose, Procedia Engineering, 173, 1169-1176

10. Dannemann M., Holeczek K., Leimert J., Friebe S., Modler N., 2019, Adapted measuring sequence for the determination of directional-dependent dynamic material properties using a bending resonance method, Polymer Testing, 79, 1-10

11. Dannemann M., TÄGer O., Modler N., 2017, Combined semi-analytical and numerical vibro-acoustic design approach for anisotropic fibre-reinforced composite structures, Journal of Sound and Vibration, 404, 1-14

12. Das S., Warren J., West D., Schexnayder S.M., 2016, Global carbon fibber composites supply chain competitiveness analysis, Technical Report, National Renewable Energy Lab (NREL), Golden Co. United States

13. Duan H., Ghidaoui M., Lee P., Tung Y., 2010, Unsteady friction and visco-elasticity in pipe fluid transients, Journal of Hydraulic Research, 48, 3, 354-362

14. ISO 4079:2017, International Organization for Standardization, (2017), Rubber hoses and hose assemblies - Textile-reinforced hydraulic types for oil-based or water-based fluids - Specification

15. Karpenko M., Bogdevičıus M., 2020, Investigation into the hydrodynamic processes of fitting connections for determining pressure losses of transport hydraulic drive, Transport, 35, 1, 108-120

16. Korunović N., Fragassa C., Marinković D., Vitković N., Trajanović M., 2019, Performance evaluation of cord material models applied to structural analysis of tires, Composite Structures, 224, 1-13

17. Langdon G.S., Karagiozova D., von Klemperer C.J., Nurick G.N., Ozinsky A., PiCKERING E.G., 2013, The air-blast response of sandwich panels with composite face sheets and polymer foam cores: experiments and predictions, International Journal of Impact Engineering, $\mathbf{5 4}, 64-82$

18. Molnár L., VÁradi K., Kovács F., 1990, FEM stress analysis of high-pressure wire reinforced hoses, Periodica Polytechnica Mechanical Engineering, 34, 3-4, 139-152

19. Pelevin L., Machyshyn G., Bogdevičius M., Karpenko M., 2016, Assessment of application high pressure hoses using a mathematical model for calculation of the load distribution between the metal braid (in Ukrainian), Mining, Constructional, Road and Melioration Machines: All Ukrainian Collection of Scientific Work, s, 88, 64-70

20. Shaw M., MacKnight W., 2005, Introduction to Polymer Viscoelasticity, 3rd Ed., John Wiley-Blackwell \& Sons Interscience, 384 p. 
21. Szymczak T, Kowalewski Z.L., 2020, Strength tests of polymer-glass composite to evaluate its operational suitability for ballistic shield plates, Eksploatacja i Niezawodność - Maintenance and Reliability, 22, 4

22. Treviso A., van Genechten B., Mundo D., Tournour M., 2015, Damping in composite materials: properties and models, Composites, Part B: Engineering, 78, 144-152

23. WANG W., YAN S., Zhao S., 2013, Experimental verification and finite element modeling of radial truck tire under static loading, Journal of Reinforced Plastics and Composites, 32, 7 , 490-498

24. Wesolowski M., Barkanov E., 2016, Air damping influence on dynamic parameters of laminated composite plates, Measurement, 85, 239-248

25. ZhaO J., Dong J., LiU Z., XiE H., 2019, Characterization method of mechanical properties of rubber materials based on in-situ stereo finite-element-model updating, Polymer Testing, 79, 1-6

Manuscript received November 12, 2020; accepted for print February 9, 2021 